\title{
Methotrexate, Paclitaxel, and Doxorubicin Radiosensitize HER2-Amplified Human Breast Cancer Cells to the Auger Electron-Emitting Radiotherapeutic Agent ${ }^{111}$ In-NLS-Trastuzumab
}

Danny L. Costantini*1,2, Daniela F. Villani*3 ${ }^{2}$, Katherine A. Vallis ${ }^{4}$, and Raymond M. Reilly ${ }^{1,5,6}$

${ }^{I}$ Department of Pharmaceutical Sciences, University of Toronto, Toronto, Ontario, Canada; ${ }^{2}$ Department of Diagnostic Imaging, Hospital for Sick Children, Toronto, Ontario, Canada; ${ }^{3}$ Faculty of Health Sciences, McMaster University, Hamilton, Ontario, Canada $;{ }^{4}$ Gray Institute for Radiation Oncology and Biology, University of Oxford, Oxford, United Kingdom; ${ }^{5}$ Department of Medical Imaging, University of Toronto, Toronto, Ontario, Canada; and ${ }^{6}$ Toronto General Research Institute, University Health Network, Toronto, Ontario, Canada

Our goal in this study was to elucidate the mechanisms by which methotrexate radiosensitizes HER2-positive human breast cancer cells to the Auger electron emitter ${ }^{111} \mathrm{In}$-trastuzumab modified with nuclear-localization sequence peptides $\left({ }^{111} \mathrm{In}-\right.$ NLS-trastuzumab) and to compare these mechanisms with the potential sensitizing effects of paclitaxel and doxorubicin when combined with this radiopharmaceutical. Methods: Experiments were performed in MDA-MB-231 human breast cancer cells, their HER2-transfected subclones $(231-\mathrm{H} 2 \mathrm{~N})$, and 2 trastuzumabresistant variants (trastuzumab-resistant-1 and -2 [TrR1 and TrR2]). Effects of coexposure of these cells to ${ }^{111} \mathrm{In}$-NLS-trastuzumab and low-dose, radiosensitizing methotrexate, paclitaxel, or doxorubicin were assessed by clonogenic cell-survival assay. Quantification of residual DNA damage was measured by the $\gamma \mathrm{H} 2 \mathrm{AX}$-immunofluorescence assay, and cell cycle distribution was measured by fluorescence-activated cell sorting analysis. The radiation-enhancement ratio was calculated as the ratio of the surviving fraction (SF) of cells treated with ${ }^{111} / \mathrm{n}$-NLStrastuzumab alone to that of cells treated concurrently with ${ }^{111}$ In-NLS-trastuzumab and methotrexate, paclitaxel, or doxorubicin. Results: A reduction in the SF in HER2-positive $231-\mathrm{H} 2 \mathrm{~N}$ $(55.7 \% \pm 1.3 \%)$ and $\operatorname{TrR} 1(62.6 \% \pm 6.5 \%)$ cells was demonstrated after exposure to ${ }^{111} \mathrm{In}-\mathrm{NLS}$-trastuzumab $(\sim 0.2 \mathrm{MBq} / \mu \mathrm{g}$, $100 \mathrm{nmol} / \mathrm{L})$ but not in MDA-MB-231 or TrR2 cells expressing low levels of HER2 (SF $>90 \%, P>0.05$ ). Coadministration of methotrexate, paclitaxel, or doxorubicin enhanced the cytotoxicity of ${ }^{111}$ In-NLS-trastuzumab toward $231-\mathrm{H} 2 \mathrm{~N}$ and TrR1 cells but not toward MDA-MB-231 or TrR2 cells. The radiationenhancement ratios for methotrexate, paclitaxel, and doxorubicin for 231-H2N or TrR1 cells were 2.0-2.2, 1.6-1.8, and 2.7-2.8, respectively. Methotrexate or doxorubicin combined with ${ }^{111} \mathrm{In}$ -

Received Aug. 23, 2009; revision accepted Nov. 24, 2009.

For correspondence or reprints contact: Raymond M. Reilly, Leslie Dan

Faculty of Pharmacy, University of Toronto, 144 College St., Toronto, Ontario M5S 3M2, Canada.

E-mail: raymond.reilly@utoronto.ca

${ }^{*}$ Contributed equally to this work.

COPYRIGHT @ 2010 by the Society of Nuclear Medicine, Inc.
NLS-trastuzumab, compared to treatment with ${ }^{111} \mathrm{In}-\mathrm{NLS}$ trastuzumab alone, significantly increased residual $\gamma \mathrm{H} 2 \mathrm{AX}$ foci in 231-H2N and TrR1 cells but not in MDA-MB-231 or TrR2 cells or in any cell line treated concurrently with paclitaxel and ${ }^{111}$ InNLS-trastuzumab. Cells exposed to low-dose methotrexate accumulated in the $G_{1} / S$ phase of the cell cycle, whereas low-dose paclitaxel or doxorubicin caused cells to arrest in the $\mathrm{G}_{2} / \mathrm{M}$ phase. Conclusion: Low-dose methotrexate, paclitaxel, or doxorubicin potently sensitized HER2-overexpressing human breast cancer cells, with and without acquired trastuzumab-resistance, to the Auger electron emissions from ${ }^{111}$ In-NLS-trastuzumab through cell cycle distribution changes and in part through the inhibitory effects of these agents on DNA damage repair.

Key Words: Auger electron; radiosensitizer; trastuzumab; breast cancer; radioimmunotherapy

J Nucl Med 2010; 51:477-483

DOI: 10.2967/jnumed.109.069716

D espite the success of radioimmunotherapy for advanced lymphohematopoietic malignancies, the treatment of patients with solid tumors such as breast cancer has been limited because of the small amounts of antibody that can be targeted to tumors. Also of concern in treatment are the irradiation and killing of normal cells (e.g., bone marrow stem cells) by the moderate-energy and long-range $(2-10 \mathrm{~mm})$ $\beta$-particles emitted by ${ }^{131} \mathrm{I}$ and ${ }^{90} \mathrm{Y}$, which have been commonly conjugated to radiotherapeutic agents $(1,2)$. Therefore, considerable attention has been given to the combination of radioimmunotherapy with drugs that are known radiosensitizers and that can amplify the lethal effects of ionizing radiation on cancer cells while having minimal or no toxicity on tissues at the low concentrations used (3). 
This strategy may be especially relevant for patients whose tumors display amplification of the HER2 receptor tyrosine kinase. HER 2 overexpression occurs in $25 \%-30 \%$ of breast cancers (4), has been correlated with resistance to hormonal therapy (5-7) and chemotherapy (8), and is directly associated with poor long-term survival (4). Trastuzumab (Herceptin; Hoffmann-La Roche) is a humanized anti-HER2 monoclonal antibody approved for immunotherapy of HER2-amplified breast cancer (4). However, only $50 \%$ of patients with tumors exhibiting moderate to high $(2+$ to $3+)$ immunohistochemistry scores or having greater than 3 copies of the HER2 gene by fluorescence in situ hybridization are predicted to respond to trastuzumab when given in combination with chemotherapy $(9,10)$. Moreover, the short duration of response to trastuzumab (9-12 mo) and the rapid development of drug resistance limit the effectiveness of trastuzumab treatment in this patient population $(11,12)$. In an attempt to enhance its antineoplastic activity, our group has been studying Auger electron radioimmunotherapy of HER2-amplified breast cancer using ${ }^{111}$ In-trastuzumab modified with 13 mer peptides (CGYGPKKKRKVGG) harboring the nuclear-localization sequence (NLS) of SV-40 large T antigen, which promotes its nuclear importation after HER2-mediated internalization into breast cancer cells (13). Auger electrons are highly damaging to DNA when they decay near the cell nucleus, making them exquisitely selective and highly potent for killing targeted single cancer cells (14). Indeed, we recently reported that ${ }^{111}$ In-NLS-trastuzumab, compared with nonradiolabeled trastuzumab (Herceptin), could slow the growth of HER2-positive breast cancer xenografts in mice, with minimal harm to normal tissues, and prolong survival (15). In in vitro studies, we further found that ${ }^{111}$ In-NLStrastuzumab was able to kill breast cancer cells that are resistant to trastuzumab and that the potency of the radiopharmaceutical could be enhanced by coexposing these cells to low, noncytotoxic concentrations of methotrexate (16).

Understanding the mechanisms resulting in tumor cell radiosensitization caused by the interaction of chemotherapeutic drugs and Auger electron radiotherapeutics would be useful in the development of rational clinical protocols that combine these agents. The first objective of this study, therefore, was to elucidate the mechanisms that underlie methotrexate radiosensitization of HER2-positive breast cancer cells to ${ }^{111}$ In-NLS-trastuzumab. Methotrexate is an antifolate drug that inhibits purine de novo synthesis. This antifolate activity of methotrexate is hypothesized to impede DNA synthesis and repair and amplify the lethal effects of the Auger electron emissions from ${ }^{111}$ In-NLStrastuzumab $(17,18)$. Therefore, we examined the effects of low-dose methotrexate on cell cycle progression using fluorescence-activated cell sorting and measured DNA damage by the $\gamma \mathrm{H} 2 \mathrm{AX}$ fluorescence assay in breast cancer cells exposed to the combination of methotrexate and ${ }^{111} \mathrm{In}$ NLS-trastuzumab. Other chemotherapeutic agents, such as paclitaxel and doxorubicin, are commonly administered to breast cancer patients in combination with trastuzumab and are also known radiosensitizers (4). Therefore, we also sought to determine whether paclitaxel and doxorubicin would radiosensitize $H E R 2$-postive breast cancer cells to ${ }^{111}$ In-NLS-trastuzumab. The radiosensitizing effects of these agents, when combined with ${ }^{111}$ In-NLS-trastuzumab, were evaluated and compared with those caused by methotrexate.

\section{MATERIALS AND METHODS}

\section{Cell Culture}

MDA-MB-231 human breast cancer cells were obtained from the American Type Culture Collection, and the 231-H2N and trastuzumab-resistant 1 and 2 (TrR1 and TrR2) cell lines were kindly provided by Dr. Robert S. Kerbel (Sunnybrook Health Sciences Centre). The 231-H2N cell line was derived from MDAMB-231 cells that were transfected to stably overexpress c-erbB-2 (HER2), whereas TrR1 and TrR2 cells were isolated from 231$\mathrm{H} 2 \mathrm{~N}$ tumors in athymic mice with acquired trastuzumab resistance (19). 231-H2N and TrR1 cells express high levels of HER2 (5.0$6.0 \times 10^{5}$ receptors per cell), which is approximately 10 -fold greater than MDA-MB-231 and TrR2 cells, which express $0.4-0.6 \times$ $10^{5}$ HER2 receptors per cell (16). All cell lines were cultured in Dulbecco's minimal essential medium (Ontario Cancer Institute) supplemented with $10 \%$ fetal bovine serum (Sigma-Aldrich) containing $100 \mathrm{U}$ of penicillin per milliliter and $100 \mu \mathrm{g}$ of streptomycin per milliliter at $37^{\circ} \mathrm{C}$ in an atmosphere of $5 \% \mathrm{CO}_{2}$.

\section{Trastuzumab and Radiosensitizers}

Trastuzumab was reconstituted according to the package insert. Methotrexate and doxorubicin were prepared by dissolving $1 \mathrm{mg}$ of the drug (Sigma-Aldrich) in $1 \mathrm{~mL}$ of alkalinized ( $\mathrm{pH}$ 11.0) or neutral $(\mathrm{pH}$ 7.0) distilled, deionized water, respectively. The methotrexate stock solution was adjusted to $\mathrm{pH} 7.0$ before use. Paclitaxel (Sigma-Aldrich) was prepared by dissolving $1 \mathrm{mg}$ of the drug in $100 \mathrm{~mL}$ of dimethyl sulfoxide. Stock solutions were diluted in culture medium to the desired final concentration. The final concentration of dimethyl sulfoxide in the culture medium was $0.1 \%(\mathrm{v} / \mathrm{v})$ or less.

\section{${ }^{111}$ In-Trastuzumab Modified with NLS-Peptides}

Trastuzumab (Herceptin) was modified with synthetic 13 mer NLS-peptides (CGYGPKKKRKVGG) and labeled with ${ }^{111} \mathrm{InCl}_{3}$ (MDS-Nordion) using diethylenetriaminepentaacetic acid (DTPA) (Sigma-Aldrich) to a specific activity of $201 \pm 6 \mathrm{MBq} / \mathrm{mg}$ (13). Briefly, trastuzumab $(500 \mu \mathrm{g}, 10 \mathrm{mg} / \mathrm{mL})$ was reacted with a $10-$ fold molar excess of DTPA dianhydride for $1 \mathrm{~h}$ at room temperature before reaction with a 15 -fold molar excess of sulfo-succinimidyl4-( $N$-maleimidomethyl)cyclohexane-1-carboxylate (SMCC) (2-5 $\mathrm{mmol} / \mathrm{L})$. Maleimide-derivatized DTPA-trastuzumab was concentrated to $2-5 \mathrm{mg} / \mathrm{mL}$ and reacted overnight at $4^{\circ} \mathrm{C}$ with a $60-$ fold molar excess of NLS-peptides $(5-10 \mathrm{mmol} / \mathrm{L}$ diluted in phosphate-buffered saline [PBS], pH 7.0). DTPA-trastuzumab modified with NLS-peptides (NLS-DTPA-trastuzumab) was purified on a Sephadex-G50 minicolumn (GE Healthcare) eluted with PBS, pH 7.5. Under these conditions, 3-4 NLS-peptides were conjugated to trastuzumab at an SMCC:IgG:NLS-peptide molar ratio of 15:1:60 (13).

NLS-conjugated trastuzumab or unmodified DTPA-trastuzumab was radiolabeled by incubation of $37-111 \mathrm{MBq}$ of monoclonal antibodies with ${ }^{111} \mathrm{InCl}_{3}$ (MDS-Nordion) for $60 \mathrm{~min}$ at room 
temperature. ${ }^{111}$ In-labeled monoclonal antibodies were purified on a Sephadex-G50 minicolumn and buffer-exchanged to PBS, $\mathrm{pH}$ 7.5, using a Microcon YM-50 ultrafiltration device (Amicon; Millipore). The radiochemical purity was routinely greater than $97 \%$ as determined by instant thin-layer chromatography-silica gel (Pall Corp.) developed in $100 \mathrm{mM}$ sodium citrate, $\mathrm{pH}$ 5.0. All radioactivity measurements were made using an automatic $\gamma$-counter (Wallac Wizard-1480; Perkin Elmer).

\section{Clonogenic Assays}

Approximately $2 \times 10^{6}$ breast cancer cells were incubated with ${ }^{111} \mathrm{In}-\mathrm{NLS}$-trastuzumab (100 nmol/L) alone or concurrently with an inhibitory concentration of $10 \%\left(\mathrm{IC}_{10}\right)$ of methotrexate, paclitaxel, or doxorubicin in $1 \mathrm{~mL}$ of culture medium in microtubes for $24 \mathrm{~h}$ at $37^{\circ} \mathrm{C}$. The 24 -h time point was chosen because nuclear accumulation of ${ }^{111}$ In-NLS-trastuzumab increases for up to $24 \mathrm{~h}$ in HER2-overexpressing breast cancer cells (13). Controls consisted of cells treated with PBS ( $\mathrm{pH} 7.5)$ or cells treated with escalating doses of methotrexate, paclitaxel, or doxorubicin (the concentrations of the tested chemotherapeutic drugs ranged from 0.01 to $100 \mu \mathrm{mol} / \mathrm{L}$ ). For treatments including methotrexate, cells were serum-starved by lowering the serum concentration from $10 \%$ to $1 \%$ to reduce the concentrations of thymidine, 5-methyl tetrahydrofolate, and purine ribonucleosides that counteract the effects of methotrexate (20). After treatment, the cells were centrifuged at $1,000 \mathrm{~g}$ for $5 \mathrm{~min}$ and washed twice with normal culture medium containing $10 \%$ serum. Sufficient cells were then plated in triplicate in 12-well plates and cultured in normal medium at $37^{\circ} \mathrm{C}$. After $10-14 \mathrm{~d}$, the dishes were stained with methylene blue, and colonies of 50 cells or more were counted. The surviving fraction (SF) was calculated by dividing the number of colonies formed for treated cells by the number for untreated cells. Survival curves were derived for cells treated with methotrexate, paclitaxel, or doxorubicin by plotting the SF values versus the log molar concentration of agent used. The inhibitory concentrations of $50 \%\left(\mathrm{IC}_{50}\right)$ and $\mathrm{IC}_{10}$ were estimated with Origin 6.0 (Microcal Software Inc.) using the dose-response equation $\mathrm{y}=$ $\mathrm{A} 1+\left[(\mathrm{A} 2-\mathrm{A} 1) /\left(1+10^{(\log \mathrm{EC} 50-\mathrm{x}) \times \mathrm{p}}\right]\right.$, where $\mathrm{p}$ is the slope (set to -1 ), and A1 and A2 are the amplitudes of the baseline and maximum response, respectively. The radiation-enhancement ratio (RER) was determined by dividing the SF of cells treated with ${ }^{111}$ In-NLS-trastuzumab alone by that of cells treated concurrently with ${ }^{111}$ In-NLS-trastuzumab and methotrexate, paclitaxel, or doxorubicin. An RER greater than 1 indicated radiosensitization $(16,21)$.

\section{Cell Cycle Analysis}

Cells were plated into 100-mm tissue culture plates (Sarstedt Inc.) at a density of $1 \times 10^{6}$ cells per plate and cultured overnight. Control cells and cells treated with methotrexate, paclitaxel, or doxorubicin were incubated in $10 \mathrm{~mL}$ of medium in $100-\mathrm{mm}$ cell culture dishes for $24 \mathrm{~h}$ at $37^{\circ} \mathrm{C}$. Treated and control cells were then suspended in $300 \mu \mathrm{L}$ of PBS and fixed with $700 \mu \mathrm{L}$ of $100 \%$ icecold ethanol for $1 \mathrm{~h}$. The cells were then washed, resuspended with $10 \mathrm{mg}$ of RNase (Invitrogen) per milliliter, and stained with propidium iodide $(25 \mathrm{mg} / \mathrm{mL}$; Sigma-Aldrich) in $100 \mu \mathrm{L}$ of PBS, $\mathrm{pH} 7.5$, for $1 \mathrm{~h}$ at $37^{\circ} \mathrm{C}$. The DNA content was analyzed with a flow cytometer (BD FACSCalibur), and the distribution of cells in the different phases of the cell cycle was determined.

\section{Measurement of DNA Damage}

The ability of ${ }^{111}$ In-NLS-trastuzumab alone or combined with methotrexate, paclitaxel, or doxorubicin to cause DNA double- strand breaks (DSBs) in breast cancer cells was evaluated using the $\gamma \mathrm{H} 2 \mathrm{AX}$-assay, which detects phosphorylation of histone$\mathrm{H} 2 \mathrm{AX}$ at serine-139 $(\gamma \mathrm{H} 2 \mathrm{AX})$ at sites of DSBs as discrete nuclear foci using $\gamma \mathrm{H} 2 \mathrm{AX}$-specific antibodies (22). Control cells were treated with methotrexate, paclitaxel, doxorubicin, or unlabeled trastuzumab alone or the combination of unlabeled trastuzumab and methotrexate, paclitaxel, or doxorubicin. Cells were cultured overnight in $1 \mathrm{~mL}$ of medium containing ${ }^{111} \mathrm{In}$ NLS-trastuzumab (100 nmol/L) alone or combined with methotrexate, paclitaxel, or doxorubicin. Exactly $24 \mathrm{~h}$ after the incubation period, cells were fixed with $2 \%$ paraformaldehyde

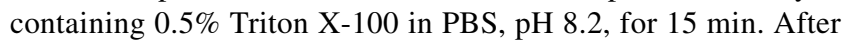
three 10 -min washes with PBS, pH 7.5, containing $0.5 \%$ bovine serum albumin and $0.2 \%$ polysorbate- 20 , the cells were permeabilized for $15 \mathrm{~min}$ with $\mathrm{PBS}, \mathrm{pH} 8.2$, containing $0.5 \%$ Nonidet P-40 (Sigma-Aldrich) and blocked for $1 \mathrm{~h}$ in $2 \%$ bovine serum albumin and $1 \%$ donkey serum. The slides were then incubated with antiphospho- $\gamma \mathrm{H} 2 \mathrm{AX}$ (1:800; Upstate Biotechnology) in $3 \%$ bovine serum albumin overnight at $4{ }^{\circ} \mathrm{C}$ and then with AlexaFluor-488 antimouse IgG (Molecular Probes) for 45 min at room temperature. All slides were mounted with Vectashield medium containing 4,6-diamidino-2-phenylindole (DAPI) (Vector Laboratories) and kept at $4{ }^{\circ} \mathrm{C}$ overnight. Images were taken with an inverted LSM510 confocal microscope (Carl Zeiss) at the Advanced Optical Microscopy Facility (Princess Margaret Hospital). Excitation was at $364 \mathrm{~nm}$ or $488 \mathrm{~nm}$ for visualization of DAPI or AlexaFluor-488, using 385- to 470-nm and 505- to 550$\mathrm{nm}$ emission filters, respectively. For imaging of $\gamma \mathrm{H} 2 \mathrm{AX}, 10-15$ $z$-stack images at approximately $1-\mu \mathrm{m}$ intervals were acquired throughout the entire cell nucleus, merged using LSM-Viewer software (version, 3.5.0.376; Zeiss), and stored as .tiff files. The number of $\gamma \mathrm{H} 2 \mathrm{AX}$-foci present in each cell was counted manually using ImageJ software (version, 1.36b; National Institutes of Health) as described previously (23).

\section{Statistical Methods}

Data are presented as mean \pm SEM. Statistical comparisons were made using the Student $t$ test. $P<0.05$ was considered significant.

\section{RESULTS}

\section{Effect of Methotrexate, Paclitaxel, and Doxorubicin} on Survival of Breast Cancer Cells

MDA-MB-231, 231-H2N, TrR1, and TrR2 human breast cancer cells were incubated with increasing concentrations of methotrexate, paclitaxel, and doxorubicin for $24 \mathrm{~h}$ to determine a low, relatively noncytotoxic concentration of drug that resulted in survival of $90 \%$ or more cells (i.e., $\mathrm{IC}_{10}$ ) by clonogenic assay. There was a strong dosedependent decrease in colony formation of the different breast cancer cells treated with increasing amounts of chemotherapeutic agent. Table 1 shows the $\mathrm{IC}_{50}$ and $\mathrm{IC}_{10}$ values of each agent for each cell line; $\mathrm{IC}_{10}$ values ranged between 0.01 and $12 \mathrm{mmol} / \mathrm{L}, 0.02$ and $0.14 \mathrm{mmol} / \mathrm{L}$, and 0.02 and $0.19 \mathrm{mmol} / \mathrm{L}$ for methotrexate, paclitaxel, and doxorubicin, respectively. These $\mathrm{IC}_{10}$ doses were chosen to evaluate the radiosensitizing effect of combined treatment of low-dose chemotherapy with ${ }^{111}$ In-NLS-trastuzumab. 
TABLE 1. $I C_{10}$ and $I C_{50}$ Values for Methotrexate, Paclitaxel, and Doxorubicin on MDA-MB-231, 231-H2N, TrR1, and TrR2 Human Breast Cancer Cells

\begin{tabular}{|c|c|c|c|}
\hline Cell line & Methotrexate* & Paclitaxel & Doxorubicin \\
\hline \multicolumn{4}{|l|}{ MDA-MB-231 } \\
\hline $\mathrm{IC}_{10}(\mu \mathrm{mol} / \mathrm{L})$ & $1.01 \pm 0.01$ & $0.07 \pm 0.03$ & $0.19 \pm 0.08$ \\
\hline $\mathrm{IC}_{50}(\mu \mathrm{mol} / \mathrm{L})$ & $103.3 \pm 13.4$ & $0.32 \pm 0.13$ & $1.26 \pm 0.39$ \\
\hline \multicolumn{4}{|l|}{$231-\mathrm{H} 2 \mathrm{~N}$} \\
\hline $\mathrm{IC}_{10}(\mu \mathrm{mol} / \mathrm{L})$ & $12.0 \pm 0.23$ & $0.14 \pm 0.10$ & $0.02 \pm 0.004$ \\
\hline $\mathrm{IC}_{50}(\mu \mathrm{mol} / \mathrm{L})$ & $120.8 \pm 23.3$ & $1.36 \pm 0.24$ & $0.16 \pm 0.04$ \\
\hline \multicolumn{4}{|l|}{ TrR1 } \\
\hline $\mathrm{IC}_{10}(\mu \mathrm{mol} / \mathrm{L})$ & $0.01 \pm 0.001$ & $0.12 \pm 0.03$ & $0.03 \pm 0.01$ \\
\hline $\mathrm{IC}_{50}(\mu \mathrm{mol} / \mathrm{L})$ & $0.13 \pm 0.01$ & $2.01 \pm 0.47$ & $0.55 \pm 0.25$ \\
\hline \multicolumn{4}{|l|}{ TrR2 } \\
\hline $\mathrm{IC}_{10}(\mu \mathrm{mol} / \mathrm{L})$ & $1.13 \pm 0.16$ & $0.02 \pm 0.01$ & $0.02 \pm 0.003$ \\
\hline $\mathrm{IC}_{50}(\mu \mathrm{mol} / \mathrm{L})$ & $102.4 \pm 10.7$ & $0.27 \pm 0.06$ & $0.21 \pm 0.08$ \\
\hline
\end{tabular}

*Values were reported previously in Costantini et al. (16).

Results are expressed as mean \pm SEM of 3 measurements performed in duplicate.

\section{Effect of ${ }^{111}$ In-NLS-Trastuzumab Combined with}

Low-Dose Methotrexate, Paclitaxel, or Doxorubicin on Clonogenic Survival

The SF of the 4 cell lines treated for $24 \mathrm{~h}$ with ${ }^{111} \mathrm{In}$ NLS-trastuzumab $(100 \mathrm{nmol} / \mathrm{L})$ alone or combined with the $\mathrm{IC}_{10}$ concentrations for methotrexate, paclitaxel, and doxorubicin was measured in clonogenic assays. Compared with no ${ }^{111}$ In-NLS-trastuzumab exposure, exposure to ${ }^{111} \mathrm{In}$ NLS-trastuzumab significantly decreased the SF for 231$\mathrm{H} 2 \mathrm{~N}$ and $\mathrm{TrR} 1$ cells $(55.6 \% \pm 1.3 \%$ and $74.1 \% \pm 5.4 \%$, respectively) that express intermediate to high levels of HER 2 but not for MDA-MB-231 or TrR2 cells $(97.9 \% \pm$ $7.2 \%$ and $89.5 \% \pm 3.8 \%$, respectively) that express low levels of HER2 (16) (Fig. 1). The effect of a 24-h treatment with ${ }^{111}$ In-NLS-trastuzumab combined with low-dose methotrexate, paclitaxel, or doxorubicin (i.e., the $\mathrm{IC}_{10}$ dose of drug) on the SF of cells was then measured. The combined treatment, compared with ${ }^{111}$ In-NLS-trastuzumab alone, caused an even greater reduction in the SF of 231-H2N and TrR1 cells, with doxorubicin causing the greatest decrease in the SF in both cell lines (Fig. 1). In contrast, the combined treatment, compared with treatment with ${ }^{111}$ In-NLS-trastuzumab alone, had little effect on the SF of MDA-MB-231 and TrR2 cells. The RERs for lowdose chemotherapy combined with ${ }^{111}$ In-NLS-trastuzumab are shown in Table 2. The greatest RERs were observed for 231-H2N and TrR1 cells when ${ }^{111}$ In-NLS-trastuzumab was combined with doxorubicin (RER, 2.7-2.8), followed by cotreatment with methotrexate (RER, 2.0-2.2) and paclitaxel (RER, 1.6-1.8).

\section{DNA Damage Induced by ${ }^{111}$ In-NLS-Trastuzumab} Combined with Methotrexate, Paclitaxel, or Doxorubicin

A 4- to 5-fold increase in the number of residual $\gamma \mathrm{H} 2 \mathrm{AX}$-foci $24 \mathrm{~h}$ after incubation with ${ }^{111}$ In-NLS-trastu- zumab (100 nmol/L), compared with after no incubation, was observed in $231-\mathrm{H} 2 \mathrm{~N}(14.0 \pm 2.6$ foci/nucleus vs. $2.7 \pm$ 0.5 foci/nucleus, $P<0.05)$ and $\operatorname{TrR} 1$ cells $(15.0 \pm 2.1$ foci/ nucleus vs. $4.1 \pm 0.7$ foci/nucleus, $P<0.05$ ) (Fig. 2). In contrast, treatment with ${ }^{111}$ In-NLS-trastuzumab did not significantly increase the formation of residual $\gamma \mathrm{H} 2 \mathrm{AX}$ foci in MDA-MB-231 or TrR2 cells $(5.7 \pm 1.1$ foci/nucleus and $5.6 \pm 1.1$ foci/nucleus, respectively), compared with $231-\mathrm{H} 2 \mathrm{~N}$ or $\mathrm{TrR} 1$ cells, likely because of the 10 -fold lower expression of HER2. 231-H2N and TrR1 cells exposed to a low dose of methotrexate or doxorubicin in combination with ${ }^{111} \mathrm{In}$-NLS-trastuzumab, compared with cells exposed to either agent alone, showed a higher number of $\gamma \mathrm{H} 2 \mathrm{AX}-$ foci $(231-\mathrm{H} 2 \mathrm{~N}$ : $21.8 \pm 2.4$ foci/nucleus and $21.4 \pm 2.4$ foci/nucleus, respectively; TrR1: $24.3 \pm 3.3$ and $23.0 \pm$ 2.2 , respectively) $(P<0.05)$. However, the combination of low-dose paclitaxel and ${ }^{111}$ In-NLS-trastuzumab, compared with treatment with ${ }^{111}$ In-NLS-trastuzumab alone, did not significantly increase the number of residual $\gamma \mathrm{H} 2 \mathrm{AX}$-foci in these cells $(231-\mathrm{H} 2 \mathrm{~N}: 17.8 \pm 1.6$ foci/nucleus; TrR1: $15.1 \pm 1.1$ foci/nucleus, $P>0.05$ ). There was a modest increase in the formation of $\gamma \mathrm{H} 2 \mathrm{AX}$-foci in MDA-MB-231 and TrR2 cells exposed to ${ }^{111}$ In-NLS-trastuzumab and chemotherapy, compared with cells exposed to only 1 of these agents, but this increase did not reach the level of statistical significance. Compared with control untreated cells, cells treated with an equivalent dose of methotrexate, paclitaxel, doxorubicin, or unlabeled trastuzumab alone, or the combination of unlabeled trastuzumab and methotrexate, paclitaxel, or doxorubicin, did not show significantly higher $\gamma \mathrm{H} 2 \mathrm{AX}$ foci/nucleus (data not shown).

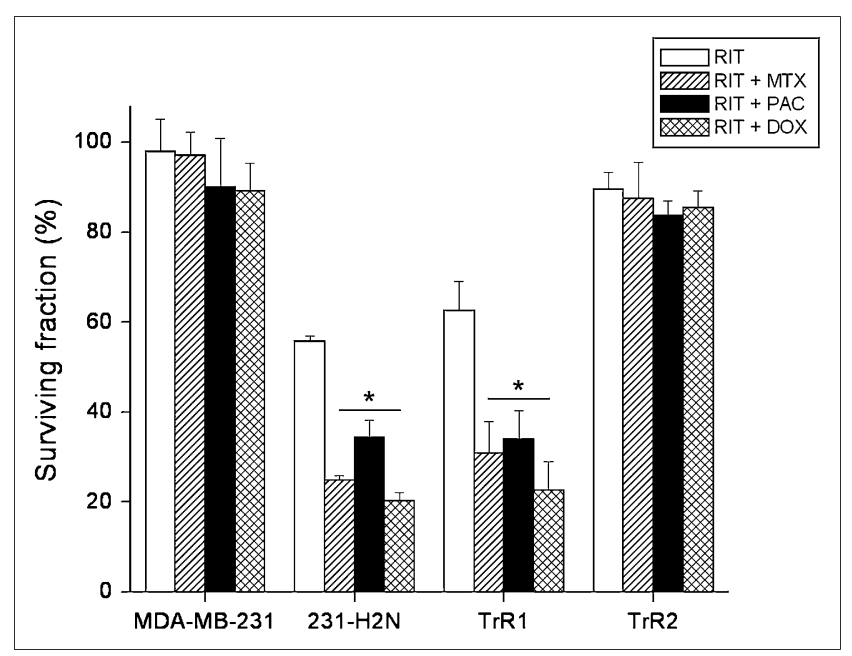

FIGURE 1. SFs of MDA-MB-231, 231-H2N, TrR1, and TrR2 human breast cancer cells after treatment with ${ }^{111} \mathrm{In}-\mathrm{NLS}-$ trastuzumab alone (radioimmunotherapy $[R I T])(\sim 0.2 \mathrm{MBq} / \mu \mathrm{g}$, $100 \mathrm{nmol} / \mathrm{L})$ or ${ }^{111} \mathrm{In}-\mathrm{NLS}$-trastuzumab combined with $\mathrm{IC}_{10}$ concentrations of methotrexate (MTX) (RIT + MTX), paclitaxel (PAC) (RIT + PAC), or doxorubicin (DOX) (RIT + DOX). IC $_{10}$ values of each drug for each cell line are shown in Table 1. ${ }^{\star} P<0.05$, compared with RIT. 
TABLE 2. Radiation Enhancement Ratio (RER) for

Methotrexate, Paclitaxel, and Doxorubicin on Human

Breast Cancer Cells When Combined with

${ }^{111}$ In-NLS-Trastuzumab

\begin{tabular}{lccc}
\multicolumn{1}{c}{ Cell line } & Methotrexate & Paclitaxel & Doxorubicin \\
MDA-MB-231 & 1.0 & 1.0 & 1.1 \\
231-H2N & 2.2 & 1.6 & 2.7 \\
TrR1 & 2.0 & 1.8 & 2.8 \\
TrR2 & 1.0 & 1.0 & 1.0
\end{tabular}

RERs were determined by dividing SF of cells treated with ${ }^{111} \mathrm{In}-\mathrm{NLS}$-trastuzumab alone ( $\left.0.2 \mathrm{MBq} / \mu \mathrm{g}, 100 \mathrm{nmol} / \mathrm{L}\right)$ by that of cells treated concurrently with ${ }^{111}$ In-NLS-trastuzumab and $I \mathrm{I}_{10}$ dose for methotrexate, paclitaxel, or doxorubicin. $I \mathrm{C}_{10}$ values for each drug on each cell line are shown in Table 1.

\section{Cell Cycle Arrest by Methotrexate, Paclitaxel,} and Doxorubicin

As shown in Supplemental Figure 1 (supplemental materials are available online only at http://jnm.snmjournals.org), low-dose methotrexate, paclitaxel, and doxorubicin caused a major redistribution of cells in the cell cycle. All cell lines, except for $\operatorname{TrR} 2$ cells, were arrested in the $\mathrm{G}_{1} / \mathrm{S}$ phase when incubated for $24 \mathrm{~h}$ with low-dose methotrexate. This arrest was accompanied by a significant decrease in the percentage of cells in the $\mathrm{G}_{2} / \mathrm{M}$ phase. In contrast, 24-h incubation with low-dose paclitaxel and doxorubicin caused all 4 cell lines to arrest in the $\mathrm{G}_{2} / \mathrm{M}$ phase of the cell cycle, accompanied by a significant decrease of cells in the $\mathrm{G}_{1} / \mathrm{S}$ phase.

\section{DISCUSSION}

Considerable attention has been given to combining radioimmunotherapy with chemotherapeutic agents that are known radiosensitizers or have other potential additive or synergistic properties (24). The chemotherapeutic agent is usually given at a reduced dose or modified schedule, primarily to enhance the radiosensitivity of cancer cells and improve the efficacy of radioimmunotherapy without increased cytotoxicity. Previously, we examined this approach using low, noncytotoxic concentrations of methotrexate to radiosensitize $H E R 2$-postive breast cancer cells to the high-linear-energy-transfer Auger electron radiation emitted by ${ }^{111}$ In-NLS-trastuzumab (16). The $\mathrm{IC}_{50}$ for ${ }^{111}$ In-NLS-trastuzumab against $231-\mathrm{H} 2 \mathrm{~N}$ and TrR1 human breast cancer cells treated concurrently with low-dose methotrexate was 5-fold lower than that for cells treated with radiopharmaceutical alone $(28 \mathrm{nmol} / \mathrm{L}$ and $14 \mathrm{nmol} / \mathrm{L}$ vs. $140 \mathrm{nmol} / \mathrm{L}$ and $70 \mathrm{nmol} / \mathrm{L}$, respectively). These findings suggested that radiosensitizing chemotherapy combined with targeted Auger electron radiotherapy can enhance cytotoxicity, but the mechanism underlying this radiosensitization remained unknown. Therefore, we sought in the current study to determine the causes mediating methotrexate radiosensitization and to explore the potential sensitizing effects of paclitaxel and doxorubicin because these agents are commonly administered in combination with trastuzumab (i.e., Herceptin) to patients with HER2positive breast cancer (4). The results presented here confirm the ability of methotrexate to selectively radiosensitize HER2-overexpressing breast cancer cells (i.e., 231$\mathrm{H} 2 \mathrm{~N}$ and $\operatorname{TrR} 1)$ to ${ }^{111}$ In-NLS-trastuzumab and further demonstrate that the cytotoxicity of this radiopharmaceutical can be enhanced by the coexposure of these cells to low, noncytotoxic concentrations of paclitaxel or doxorubicin. The radiosensitizing effects were shown to be mediated through cell cycle distribution changes and in part through the inhibitory effects of these agents on DNA repair, as evidenced by the increase in $\gamma \mathrm{H} 2 \mathrm{AX}$ foci in the cells.

The main intracellular target of methotrexate is dihydrofolate reductase, an enzyme that participates in reduced

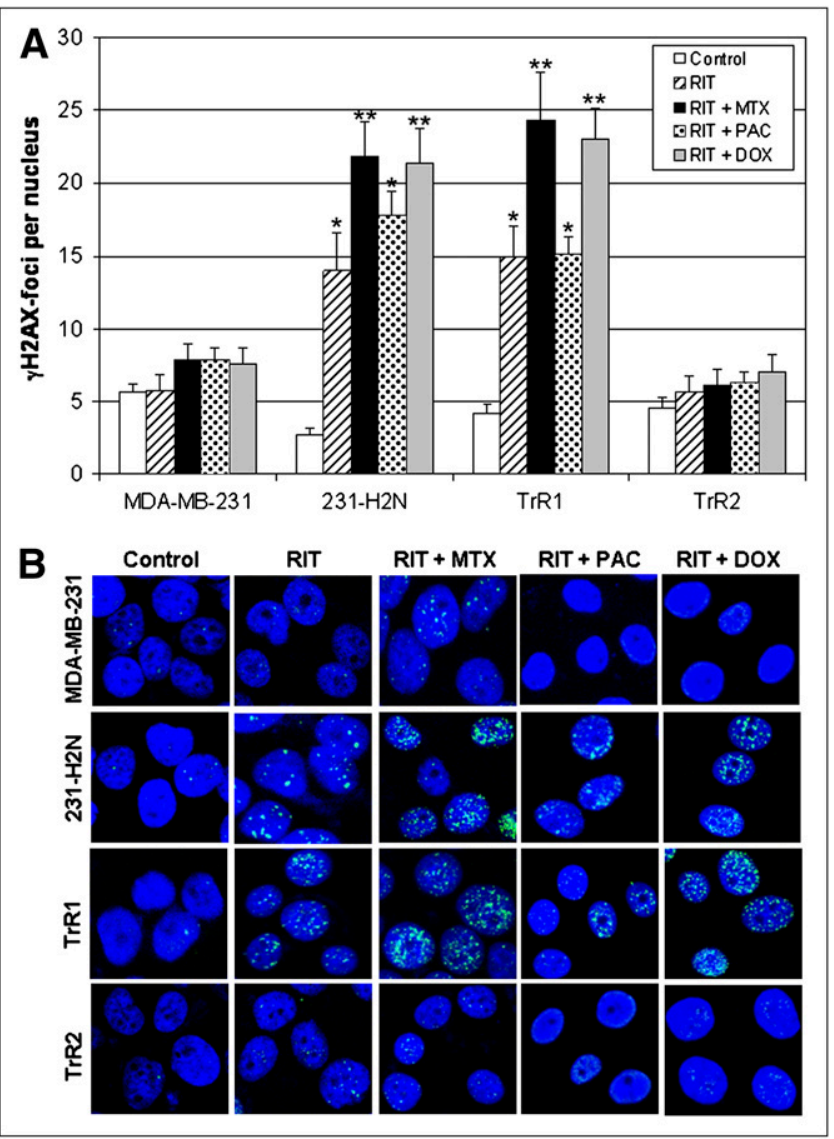

FIGURE 2. (A) Residual $\gamma \mathrm{H} 2 \mathrm{AX}$-foci in MDA-MB-231, 231H2N, TrR1, and TrR2 human breast cancer cells $24 \mathrm{~h}$ after exposure to ${ }^{111} \mathrm{In}-\mathrm{NLS}$-trastuzumab alone (radioimmunotherapy [RIT]) $(100 \mathrm{nmol} / \mathrm{L})$ or ${ }^{111} \mathrm{In}-\mathrm{NLS}$-trastuzumab combined with $\mathrm{IC}_{10}$ concentrations of methotrexate (MTX) (RIT + MTX), paclitaxel (PAC) (RIT + PAC), or doxorubicin (DOX) (RIT + DOX). Number of $\gamma \mathrm{H} 2 \mathrm{AX}$-foci per nucleus is shown as mean \pm SEM, and at least 30 nuclei were assessed for $\gamma \mathrm{H} 2 \mathrm{AX}$-foci for each treatment. (B) Induction of $\gamma \mathrm{H} 2 \mathrm{AX}$-foci (green) $24 \mathrm{~h}$ after exposure to ${ }^{111} \mathrm{In}$-NLS-trastuzumab alone or concurrently with MTX, PAC, or DOX. Nuclear DNA was stained with DAPI (blue). ${ }^{*} P<0.05$, compared with control, or ${ }^{\star \star} P<0.05$, compared with ${ }^{111}$ In-NLS-trastuzumab. 
folate metabolism (18). Methotrexate is thought to radiosensitize cells through its effect on the depletion of reduced folates required for the production of purine deoxyribonucleotides and thymidylate necessary for DNA synthesis and repair $(18,25)$. Indeed, the low, noncytotoxic concentration of methotrexate that was determined in clonogenic assays to radiosensitize $231-\mathrm{H} 2 \mathrm{~N}$ and $\mathrm{TrR} 1$ breast cancer cells to ${ }^{111}$ In-NLS-trastuzumab was found to cause these cells to accumulate in the $G_{1} / S$ phase of the cell cycle, possibly through the depletion of intracellular purine nucleotide pools (Supplemental Fig. 1). Although we did not attempt to assess the distinction between cells in the G1 and early S phases of the cell cycle, a more accurate estimate may be obtained by measuring the DNA content of bromodeoxyuridine-labeled S-phase cells using dual-parameter flow cytometry (26). Nevertheless, the extent of DNA damage $\left(\gamma \mathrm{H} 2 \mathrm{AX}\right.$-foci) in these cells at $24 \mathrm{~h}$ after exposure to ${ }^{111} \mathrm{In}-$ NLS-trastuzumab was enhanced by coexposure to methotrexate (Fig. 2), suggesting that nucleotide depletion by methotrexate can indirectly affect the repair of DNA damage in cells exposed to Auger electron radiation. Alternatively, chemotherapeutic radiosensitizers may produce their effect mainly by direct action on DNA (17). Doxorubicin, for example, forms complexes with DNA by intercalation between base pairs, interfering with DNA polymerase and topoisomerase II activity, and inhibits enzyme repair of radiation-induced DNA DSBs (27). Indeed, the addition of low-concentration doxorubicin to

${ }^{111}$ In-NLS-trastuzumab, compared with cells treated with either of these agents alone, induced more DNA damage and increased the killing of $231-\mathrm{H} 2 \mathrm{~N}$ and TrR 1 cells. This result is in agreement with the observations by Supiot et al. (21), who demonstrated synergy between doxorubicin and $\alpha$-particle radioimmunotherapy on induction of DNA damage and cell death in RPMI8226 myeloma cells. The powerful arrest of 231-H2N and TrR1 cells in the radiosensitive $\mathrm{G}_{2} / \mathrm{M}$ phase of the cell cycle induced by doxorubicin (Supplemental Fig. 1) may also account for the observed increase in DNA damage and reduction in the SF of these cells after coexposure with ${ }^{111}$ In-NLS-trastuzumab.

Paclitaxel also caused 231-H2N and TrR1 cells to arrest in the radiosensitive $\mathrm{G}_{2} / \mathrm{M}$ phase of the cell cycle (Supplemental Fig. 1) (28). However, the level of paclitaxel radiosensitization, combined with ${ }^{111}$ In-NLS-trastuzumab, was moderately lower than with combinations of the radiopharmaceutical with methotrexate or doxorubicin. For example, the RER for the addition of paclitaxel to ${ }^{111}$ In-NLS-trastuzumab for $231-\mathrm{H} 2 \mathrm{~N}$ and TrR1 cells was $1.6-1.8$, versus $2.0-2.2$ and $2.7-2.8$ for combinations with methotrexate and doxorubicin, respectively (Table 2). The lower level of radiosensitization caused by paclitaxel also correlated with fewer residual $\gamma \mathrm{H} 2 \mathrm{AX}$-foci in $231-\mathrm{H} 2 \mathrm{~N}$ and TrR1 cells after cotreatment with ${ }^{111}$ In-NLS-trastuzumab (Fig. 2). This correlation is consistent with the fact that paclitaxel does not promote DNA damage but instead binds to and promotes the polymerization of tubulin, which interferes with normal microtubule breakdown (29). Moreover, paclitaxel has been shown to trigger apoptosis, possibly by inducing the phosphorylation and inactivation of the antiapoptotic factors $\mathrm{Bcl}-2$ and $\mathrm{Bcl}-\mathrm{x}_{\mathrm{L}}(30)$. It is possible that paclitaxel-mediated radiosensitization of HER2-positive breast cancer cells results from mechanisms unrelated to DNA DSB induction. Other DNA-incorporated, Auger electron-emitting radiopharmaceuticals, such as 5-[ $\left.{ }^{125} \mathrm{I}\right]$ iodo- $2^{\prime}$-deoxyuridine, have been shown to promote apoptosis through a caspase-3-mediated process (31). Thus, chemotherapeutic agents that amplify the apoptotic response in HER2-positive breast cancer cells exposed to Auger electron radiation may also be effective in causing radiosensitization.

Future studies examining low-dose chemotherapy radiosensitization and ${ }^{111}$ In-NLS-trastuzumab in vivo will need to assess the dose-limiting toxicities on normal tissues associated with this combined treatment. Indeed, one limitation of this regimen is that the radiosensitization effect might not be exclusive to tumor cells, particularly when the radiopharmaceutical is administered at high doses. However, minimal toxicity toward MDA-MB-231 and TrR2 cells expressing low levels of $H E R 2$ was observed from this combination, suggesting that radiosensitization may be specific for cells overexpressing HER2 (i.e., HER2-amplified breast cancer cells). Moreover, the feasibility of combining radiosensitizing chemotherapy with radioimmunotherapy has been demonstrated previously in preclinical and clinical studies (32). For example, DeNardo et al. (33) examined the effect of combining paclitaxel with radioimmunotherapy using ${ }^{90} \mathrm{Y}$-chimeric anti-L6 antibody $\left({ }^{90} \mathrm{Y}\right.$ ChL6) in mice bearing HBT-3477 human breast cancer xenografts. Paclitaxel administered 6 or $24 \mathrm{~h}$ after radioimmunotherapy did not substantially increase normal-tissue toxicity but resulted in cures or complete responses in all (46/46) treated mice, whereas only $21 \%$ (6/29) of animals were cured when paclitaxel was given before ${ }^{90} \mathrm{Y}-\mathrm{ChL} 6$ (33). Thus, the optimal combination and scheduling of lowdose chemotherapy and ${ }^{111}$ In-NLS-trastuzumab needs to be determined because the radiosensitizing effect may be highly dependent on the timing of administration of the chemotherapeutic drug relative to radioimmunotherapy. One approach may be to administer the radiotherapeutic agent, wait for $72 \mathrm{~h}$ for optimal tumor uptake and elimination from normal tissues (13), and then administer these low-molecular-weight radiosensitizers, which are expected to equilibrate rapidly between the plasma and the tissues (including tumor), thereby providing concurrently high concentrations of radioactivity and radiosensitizers.

The trastuzumab-resistant TrR1 cells (19) were efficiently killed by ${ }^{111}$ In-NLS-trastuzumab, and the toxicity was enhanced by coexposure to radiosensitizing concentrations of methotrexate, paclitaxel, or doxorubicin (Fig. 1). Combination therapy with low-dose chemotherapy and ${ }^{111}$ In-NLS-trastuzumab may, therefore, offer a route to overcoming the challenges associated with trastuzumab 
resistance. Indeed, only about half of patients with HER2overexpressing metastases respond to trastuzumab when combined with paclitaxel or doxorubicin, and in almost all initially responding patients, resistance to trastuzumab develops within a year $(11,12)$. There have been few studies that have examined the combination of radiotherapeutics that emit high-linear-energy transfer radiation, such as Auger electron-emitting ${ }^{111}$ In-NLS-trastuzumab and radiosensitizers (34). Achieving such a synergistic interaction by combining radiosensitizing chemotherapy and ${ }^{111} \mathrm{In}-\mathrm{NLS}$ trastuzumab, compared with either of these therapies alone, could dramatically improve the response.

\section{CONCLUSION}

Methotrexate, paclitaxel, and doxorubicin radiosensitize trastuzumab-sensitive and trastuzumab-resistant human breast cancer cell lines overexpressing HER 2 to ${ }^{111} \mathrm{In}-\mathrm{NLS}$ trastuzumab, and the combination of radiosensitizing chemotherapy and targeted Auger electron radiotherapy with this radiopharmaceutical, compared with either of these agents alone, is more cytotoxic to these cells. The radiosensitizing effects of these agents were shown to be mediated through changes in cell cycle distribution and partly through inhibition of DNA repair (methotrexate and doxorubicin) after exposure to ${ }^{111}$ In-NLS-trastuzumab. These results are promising for the development of novel regimens for radioimmunotherapy of HER2-amplified breast cancer incorporating low-dose, radiosensitizing chemotherapy.

\section{ACKNOWLEDGMENTS}

This research was supported by grants 016456 and 019513 from the Canadian Breast Cancer Research Alliance, funds from the Canadian Cancer Society, and a predoctoral fellowship from the Canadian Breast Cancer Foundation (Ontario Chapter).

\section{REFERENCES}

1. DeNardo SJ, Denardo GL. Targeted radionuclide therapy for solid tumors: an overview. Int J Radiat Oncol Biol Phys. 2006;66:S89-S95.

2. Reilly RM, Sandhu J, Alvarez-Diez TM, et al. Problems of delivery of monoclonal antibodies: pharmaceutical and pharmacokinetic solutions. Clin Pharmacokinet. 1995;28:126-142.

3. Buchsbaum DJ. Experimental radioimmunotherapy. Semin Radiat Oncol. 2000;10:156-167.

4. Slamon DJ, Leyland-Jones B, Shak S, et al. Use of chemotherapy plus a monoclonal antibody against HER2 for metastatic breast cancer that overexpresses HER2. N Engl J Med. 2001;344:783-792.

5. Kolar Z, Murray PG, Zapletalova J. Expression of c-erbB-2 in node negative breast cancer does not correlate with estrogen receptor status, predictors of hormone responsiveness, or PCNA expression. Neoplasma. 2002;49:110-113.

6. Konecny G, Pauletti G, Pegram M, et al. Quantitative association between HER$2 /$ neu and steroid hormone receptors in hormone receptor-positive primary breast cancer. J Natl Cancer Inst. 2003;95:142-153.

7. Love RR, Duc NB, Havighurst TC, et al. Her-2/neu overexpression and response to oophorectomy plus tamoxifen adjuvant therapy in estrogen receptor-positive premenopausal women with operable breast cancer. J Clin Oncol. 2003;21: 453-457.

8. Nahta R, Hortobagyi GN, Esteva FJ. Growth factor receptors in breast cancer: potential for therapeutic intervention. Oncologist. 2003;8:5-17.
9. Seidman AD, Fornier MN, Esteva FJ, et al. Weekly trastuzumab and paclitaxel therapy for metastatic breast cancer with analysis of efficacy by HER2 immunophenotype and gene amplification. J Clin Oncol. 2001;19: 2587-2595.

10. van de Vijver MJ. Assessment of the need and appropriate method for testing for the human epidermal growth factor receptor-2 (HER2). Eur J Cancer. 2001; 37(suppl 1):11-17.

11. Baselga J. Clinical trials of Herceptin (trastuzumab). Eur J Cancer. 2001; 37(suppl 1):18-24.

12. Piccart M. Circumventing de novo and acquired resistance to trastuzumab: new hope for the care of ErbB2-positive breast cancer. Clin Breast Cancer. 2008; 8(suppl 3):S100-S113.

13. Costantini DL, Chan C, Cai Z, Vallis KA, Reilly RM. ${ }^{111}$ In-labeled trastuzumab (Herceptin) modified with nuclear localization sequences (NLS): an Auger electron-emitting radiotherapeutic agent for HER2/neu-amplified breast cancer. J Nucl Med. 2007;48:1357-1368.

14. Costantini DL, Hu M, Reilly RM. Peptide motifs for insertion of radiolabeled biomolecules into cells and routing to the nucleus for cancer imaging or radiotherapeutic applications. Cancer Biother Radiopharm. 2008;23:3-24.

15. Costantini DL, McLarty K, Lee H, Done SJ, Vallis KA, Reilly RM. The pharmacokinetics, normal tissue toxicity and anti-tumor effects of ${ }^{111}$ In-NLStrastuzumab in mice bearing HER2-overexpressing breast cancer xenografts [abstract]. J Nucl Med. 2009;50(suppl 2):571.

16. Costantini DL, Bateman K, McLarty K, Vallis KA, Reilly RM. Trastuzumabresistant breast cancer cells remain sensitive to the auger electron-emitting radiotherapeutic agent ${ }^{111} \mathrm{In}-\mathrm{NLS}$-trastuzumab and are radiosensitized by methotrexate. J Nucl Med. 2008;49:1498-1505.

17. Lawrence TS, Blackstock AW, McGinn C. The mechanism of action of radiosensitization of conventional chemotherapeutic agents. Semin Radiat Oncol. 2003;13:13-21.

18. Spittle MF. Methotrexate and radiation. Int J Radiat Oncol Biol Phys. 1978; 4:103-107.

19. du Manoir JM, Francia G, Man S, et al. Strategies for delaying or treating in vivo acquired resistance to trastuzumab in human breast cancer xenografts. Clin Cancer Res. 2006;12:904-916.

20. Li JC, Kaminskas E. Accumulation of DNA strand breaks and methotrexate cytotoxicity. Proc Natl Acad Sci USA. 1984;81:5694-5698.

21. Supiot S, Gouard S, Charrier J, et al. Mechanisms of cell sensitization to $\alpha$ radioimmunotherapy by doxorubicin or paclitaxel in multiple myeloma cell lines. Clin Cancer Res. 2005;11:7047s-7052s.

22. Peng M, Litman R, Jin Z, Fong G, Cantor SB. BACH1 is a DNA repair protein supporting BRCA1 damage response. Oncogene. 2006;25:2245-2253.

23. Cai Z, Vallis KA, Reilly RM. Computational analysis of the number, area and density of $\gamma$-H2AX foci in breast cancer cells exposed to ${ }^{111}$ In-DTPA-hEGF or $\gamma$-rays using Image-J software. Int J Radiat Biol. 2009;85:262-271.

24. Goldenberg DM, Sharkey RM. Advances in cancer therapy with radiolabeled monoclonal antibodies. Q J Nucl Med Mol Imaging. 2006;50:248-264.

25. Allen BG, Johnson M, Marsh AE, Dornfeld KJ. Base excision repair of both uracil and oxidatively damaged bases contribute to thymidine deprivationinduced radiosensitization. Int J Radiat Oncol Biol Phys. 2006;65:1544-1552.

26. Tsurusawa M, Niwa M, Katano N, Fujimoto T. Flow cytometric analysis by bromodeoxyuridine/DNA assay of cell cycle perturbation of methotrexatetreated mouse L1210 leukemia cells. Cancer Res. 1988;48:4288-4293.

27. Bonner JA, Lawrence TS. Doxorubicin decreases the repair of radiation-induced DNA damage. Int J Radiat Biol. 1990;57:55-64.

28. Formenti SC, Symmans WF, Volm M, et al. Concurrent paclitaxel and radiation therapy for breast cancer. Semin Radiat Oncol. 1999;9:34-42.

29. Liebmann J, Cook JA, Fisher J, Teague D, Mitchell JB. In vitro studies of Taxol as a radiation sensitizer in human tumor cells. J Natl Cancer Inst. 1994;86:441-446.

30. Blagosklonny MV, Fojo T. Molecular effects of paclitaxel: myths and reality (a critical review). Int J Cancer. 1999;83:151-156.

31. Urashima T, Nagasawa H, Wang K, Adelstein SJ, Little JB, Kassis AI. Induction of apoptosis in human tumor cells after exposure to Auger electrons: comparison with $\gamma$-ray exposure. Nucl Med Biol. 2006;33:1055-1063.

32. Wong JY. Systemic targeted radionuclide therapy: potential new areas. Int $J$ Radiat Oncol Biol Phys. 2006;66:S74-S82.

33. DeNardo SJ, Kukis DL, Kroger LA, et al. Synergy of Taxol and radioimmunotherapy with yttrium-90-labeled chimeric L6 antibody: efficacy and toxicity in breast cancer xenografts. Proc Natl Acad Sci USA. 1997;94:4000-4004.

34. Sharkey RM, Goldenberg DM. Use of antibodies and immunoconjugates for the therapy of more accessible cancers. Adv Drug Deliv Rev. 2008;60: 1407-1420. 